\title{
XVIII. Note on the measurement of the internal resistance of cells
}

\section{E. Wythe Smith}

To cite this article: E. Wythe Smith (1892) XVIII. Note on the measurement of the internal resistance of cells, Philosophical Magazine Series 5, 34:207, 173-176, DOI: 10.1080/14786449208620303

To link to this article: http://dx.doi.org/10.1080/14786449208620303

$$
\text { 曲 Published online: } 07 \text { May } 2010 .
$$

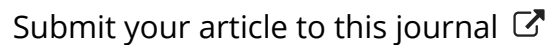

Џ Article views: 2 
Again, multiply (115) by $x$, (116) by $y,(117)$ by $z$, and add. Then integrating throughout the entire volume, we find

$$
-\iiint(\widehat{x x}+\widehat{y y}+\widehat{z z}) d x d y d z+\omega^{2} \iiint \rho\left(x^{2}+y^{2}\right) d x d y=0,
$$

the surface-integrals vanishing as before.

But by the ordinary stress-strain relations,

$$
\widehat{x x}+\widehat{y y}+\widehat{z z}=3 k \Delta,
$$

where $k$ is the bulk modulus, and thus we get

$$
\delta v=\iiint \Delta d x d y d z=\omega^{2} \mathrm{I} / 3 k,
$$

where $I$ has the same meaning as in (114).

Since

we have

$$
v=2 \mathrm{~A} l,
$$

$$
\begin{aligned}
\overline{\delta \mathrm{A}} / \mathrm{A} & =\delta v / v-\overline{\delta l} / l, \\
& =(1-\eta) \omega^{2} \rho \kappa^{2} / \mathrm{E} .
\end{aligned}
$$

Thus (111) and (114) are also proved to be absolutely true in all right cylinders rotating about their axis of figure.

The preceding formulæ by which the solution has been tested are particular cases of certain much more general results*, to whose discovery the author was led by the recognition of the coincidences pointed out in $\S 49$.

XVIII. Note on the Measurement of the Internal Resistance of Cells. By E. W Yтне Simtн†.

TN order to determine the actions which take place in an 1 accumulator during charge and discharge, it is necessary to know the working electromotive force at the different stages. This might be observed by breaking the circuit; but immediately on doing this the electromotive force varies at a very rapid rate, so that if only four or five seconds be occupied in taking the measurement an error of 25 per cent. may be made in the difference between the electromotive force and the terminal potential difference. If time-readings be taken after breaking the circuit and a curve drawn connecting E.M.F. and time, this curve may be produced back in the way described by Prof. Ayrton and others in a paper

* Cambridge Philosophical Society's Transactions, vol. xv. part iii.

† Communicated by the Physical Society : read June 24th, 1892. 
at the Institute of Electrical Engineers. But, as this method has its objections in addition to that of interrupting the circuit, it is very desirable to determine the actual working E.M.F. in some other way.

The E.M.F. could be readily obtained from the terminal P.D. and the current if the internal resistance were known. It is for the determination of this latter quantity that $I$ have devised the following modification of Mance's method. Of course this method is applicable to the measurement of the resistance of other forms of battery besides accumulators.

Fig. 1.

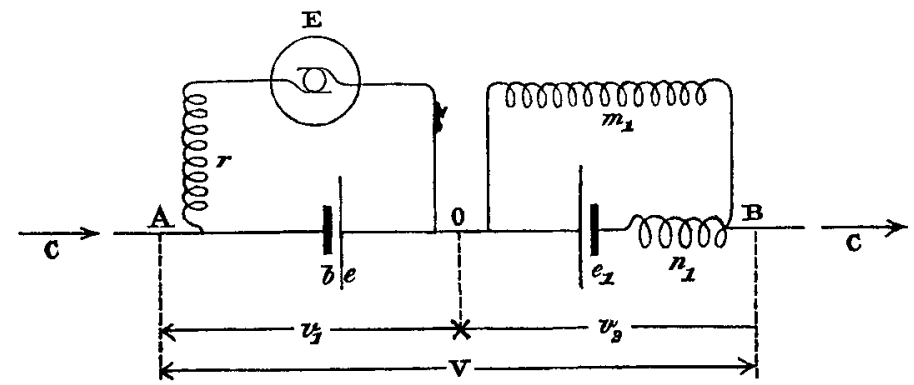

In fig. 1 let the cell of E.M.F. e, and internal resistance, $b$, be the one experimented upon, $r$ being the resistance of the external circuit which may contain an E.M.F. E, for example that of the dynamo used to charge the cell. This circuit is connected at $\mathrm{O}$ with an auxiliary circuit, in which the resistances $m_{1}$ and $n_{1}$ are so adjusted that the points $A$ and $B$ are at the same potential, the resistance of the cell of E.M.F., $e_{1}$, being included in $n_{1}$. Suppose a current, $\mathrm{C}$, from some external source to pass through both circuits in series. The P.D. between A and B will now be V. Let P.D. between A and $\mathrm{O}$ be $v_{1}$, and that between $\mathrm{O}$ and $\mathrm{B}$ be $v_{2},\left(v_{1}+v_{2}\right)=\mathrm{V}$. We have

therefore

$$
\mathrm{C}=\frac{v_{1}+e}{b}+\frac{v_{1}+\mathrm{E}}{r}=\frac{v_{2}-e_{1}}{n_{1}}+\frac{v_{2}}{m_{1}}
$$

and

$$
v_{\mathrm{1}}=\frac{b r \mathrm{C}-r e-b \mathrm{E}}{b+r}
$$

$$
\begin{aligned}
& v_{2}=\frac{m_{1} n_{1} \mathrm{C}+m_{1} e_{1}}{m_{1}+n_{1}} \\
& \mathrm{~V}=\frac{b+\mathrm{C}-r e-b \mathrm{E}}{b+r}+\frac{m_{1} n_{1} \mathrm{C}+m_{1} e_{1}}{m_{1}+n_{1}}
\end{aligned}
$$


of the Internal Resistance of Cells.

But when $\mathrm{C}=0, \mathrm{~V}=0$,

$$
\begin{aligned}
& \therefore 0=\frac{-r e-b \mathrm{E}}{b+r}+\frac{m_{1} e_{1}}{m_{1}+n_{1}} ; \\
& \therefore \mathrm{V}=\mathrm{C}\left(\frac{b r}{b+r}+\frac{m_{1} n_{1}}{m_{1}+n_{1}}\right) .
\end{aligned}
$$

If we measure the apparent distance $R_{1}$ between $A$ and $B$ by any convenient method, and if $\mathrm{C}$ be the current sent through this circuit between $A$ and $B$ by the testing arrangement, we get $R_{1}$ equal to $\frac{V}{C}$;

$$
\therefore \mathrm{R}_{1}=\frac{b r}{b+r}+\frac{m_{1} n_{1}}{m_{1}+n_{1}}
$$

Now if we have three circuits (fig. 2) connected together

Fig. 2.

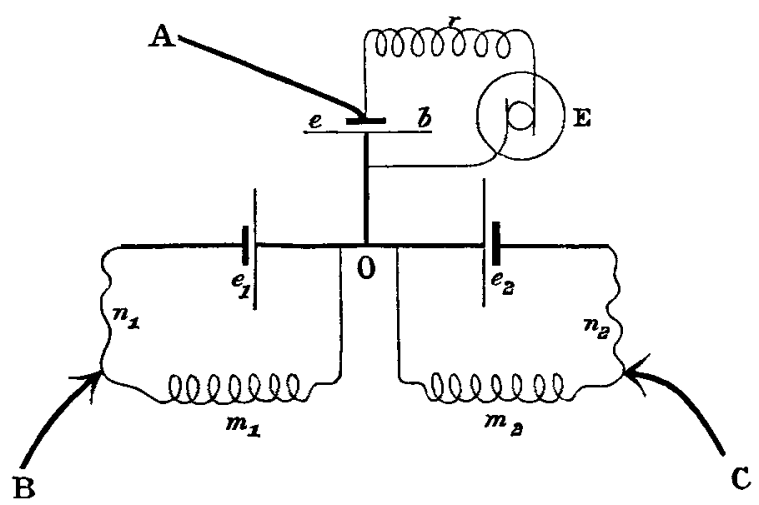

at the point 0 , the cell of E.M.F. equal to $e$ and resistance $b$ being the particular one whose resistance is required, and if the resistances $m_{1}, m_{2}, n_{1}, n_{2}$ be so adjusted that the points $\mathrm{A}, \mathrm{B}$, and $\mathrm{C}$ are at the same potential, the apparent resistances $R_{1}, R_{2}, R_{3}$ between the points $A$ and $B, A$ and $C$, and $B$ and $C$, will have the following values :-

$$
\begin{aligned}
& \mathrm{R}_{1}=\frac{b r}{b+r}+\frac{m_{1} n_{1}}{m_{1}+n_{1}}, \\
& \mathrm{R}_{2}=\frac{b r}{b+r}+\frac{m_{2} n_{2}}{m_{2}+n_{2}}, \\
& \mathrm{R}_{3}=\frac{m_{1} n_{1}}{m_{1}+n_{1}}+\frac{m_{2} n_{2}}{m_{2}+n_{2}} ;
\end{aligned}
$$




$$
\therefore \frac{l r}{b+r}=\frac{\mathbf{R}_{1}+\mathbf{R}_{2}-\mathbf{R}_{3}}{2} \text {, say, equals } x,
$$

then the required resistance of the cell,

$$
b=x+\frac{x^{2}}{r}+\frac{x^{3}}{r^{2}}+\& c .
$$

If, as in the case of an accumulator, $x$ is small compared with $r$, then

$$
b=x+\frac{x^{2}}{r}
$$

When an accumulator is discharging, taking $b=x$ gives us a a value for $b$ about 2 per cent. too low.

If the P.D. at terminals of the cell under test is greater than the E.M.F. of a single balancing cell (as is the case

Fig. $2 a$,

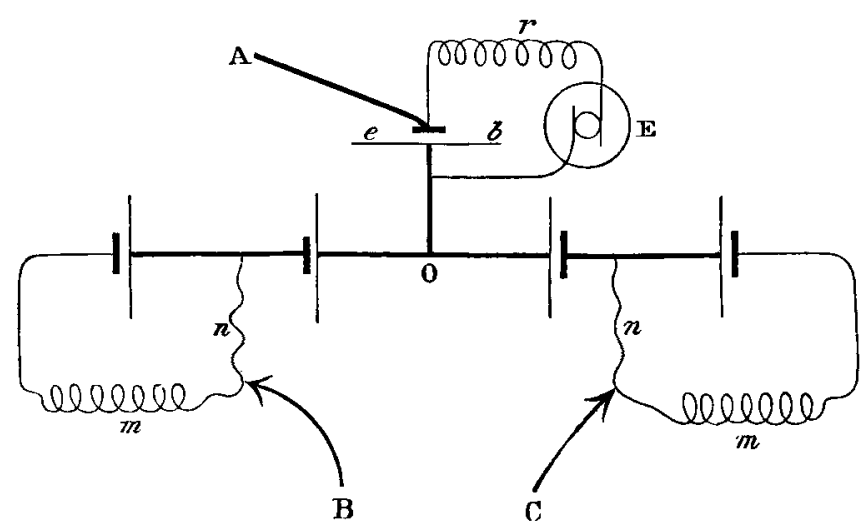

during charge) then the circuit must be modified as shown (fig. $2 a$ ):

If a Wheatstone's bridge be employed to measure $R_{1}, R_{2}$, and $R_{3}$, there will be no necessity to employ any special instrument in the testing for equality of potential of the points $A, B$, and $C$. For all that need be done is to remove an infinity plug on the bridge, close the galvanometer circuit, but not that of the testing battery, and adjust $m_{1}, m_{2}, n_{1}, n_{2}$ until the galvanometer remains at zero: 